\title{
A New Sampling Plan Using Neutrosophic Process Loss Consideration
}

\author{
Muhammad Aslam iD \\ Department of Statistics, Faculty of Science, King Abdulaziz University, Jeddah 21551, Saudi Arabia; \\ aslam_ravian@hotmail.com
}

Received: 12 April 2018; Accepted: 20 April 2018; Published: 25 April 2018

\begin{abstract}
The theory of classical statistics assumes crisp, certain, and clear observations / parameters in engineering applications. However, in such engineering applications, due to their complex functions, it may not possible to obtain clear or crisp values of certain parameters. So, there is a chance of obtaining indeterminate, imprecise, vague, and incomplete parameters. In this situation, neutrosophic statistics can be applied, which is the generalization of classical statistics. This is reduced to classical statistics when no parameters are found to be indeterminate, imprecise, vague, or incomplete in actual practice. In this paper, we design a new sampling plan using the neutrosophic approach for the process loss function. The neutrosophic non-linear problem is given and applied to determine the neutrosophic plan parameters of the proposed sampling plan. A table is given and discussed with the help of factory data.
\end{abstract}

Keywords: crisp values; fuzzy approach; neutrosophic non-linear problem; risks; process loss function

\section{Introduction}

Lot sentencing is conducted through well-defined acceptance sampling plans. The sampling is used for the acceptance or rejection of the submitted lot based on the sample information. As mentioned by [1], "because the sampling cannot guarantee that every defective item in a lot will be inspected, the sampling involves risks of not adequately reflecting the quality levels of the lot". Yen and Chang [1] designed a sampling plan that distinguishes the product that meets the upper specification limit (USL) and lower specification limit (LSL). They used the process loss index for the lot sentencing problem. Later, [2] designed a sampling plan for the process loss index using the repetitive sampling scheme. More details about sampling plans using the process loss index can be seen in [3-5]. For other variable sampling plans, see [6-9].

The sampling plans available in the literature assume that the defective proportion is a crisp value. However, in practice, it may not possible to achieve a clear proportion of the defective values. The values may be estimated from point or interval estimation using the sample information. In another case, it may not be known exactly. So, the fuzzy approach is applied to design sampling plans for the lot sentencing of the product. Afshari and Gildeh [10] employed a fuzzy sampling plan, using the multiple dependent state sampling when the defective proportion was unknown in actual practice. More details about such sampling plans can be seen in [11-19].

The sampling plans using the fuzzy approach usually assume that there is uncertainty in the defective proportion. Neutrosophic statistics is defined by [20] as the generalization of classical statistics. Classical statistics cannot be applied if there is uncertainty in the parameters/observations, see for example [20-22]. The sampling plans using the process loss index available in the literature encounter difficulty for the lot sentencing of the product. Furthermore, the sampling plans using the 
fuzzy approach can be applied when there is uncertainty in the plan parameters and observations. Therefore, it is necessary to propose a sampling plan using neutrosophic statistics.

The theory of classical statistics assumes crisp, certain, and clear observations/parameters in engineering applications. However, in such engineering applications, due to their complex functions, it may not possible to obtain clear or crisp values of certain parameters. So, there is a chance of obtaining indeterminate, imprecise, vague, and incomplete parameters. In this situation, neutrosophic statistics can be applied, which is the generalization of classical statistics. This is reduced to classical statistics when no parameters are found to be indeterminate, imprecise, vague, or incomplete in actual practice. To the best of the author's knowledge, no effort has been made to design a sampling plan using the neutrosophic approach for the process loss index. In this paper, we design a new sampling plan using the neutrosophic approach for the process loss function. The neutrosophic non-linear problem is given and applied to determine the neutrosophic plan parameters of the proposed sampling plan. A table is given and discussed with the help of factory data.

\section{Neutrosophic Process Loss Consideration}

Suppose that $X_{N i} \in\left\{X_{L}, X_{U}\right\}=i=1,2,3, \ldots, n$ represents the neutrosophic random variable with uncertainty, indeterminate, and imprecise observations. Suppose also that $\mu_{N} \in\left\{\mu_{L}, \mu_{U}\right\}$ and $\sigma_{N} \in\left\{\sigma_{L}, \sigma_{U}\right\}$ are the neutrosophic mean and standard definition (SD), respectively. Let $X_{N i} \in\left\{X_{L}, X_{U}\right\}$ have the crisp target value $T$, upper specification limit (USL), and lower specification limit (LSL). By following [23], we define the neutrosophic process loss index as:

$$
L_{N e}=\frac{\sigma_{N}^{2}}{d^{2}}+\frac{\left(\mu_{N}-T\right)^{2}}{d^{2}} ; \mu_{N} \in\left\{\mu_{L}, \mu_{U}\right\}, \sigma_{N} \in\left\{\sigma_{L}, \sigma_{U}\right\}
$$

where $d=(U S L-L S L) / 2$.

In practice, $\mu_{N}$ and $\sigma_{N}$ are unknown, so the estimated neutrosophic process loss index is defined by:

$$
\hat{L}_{N e}=\frac{S_{N}^{2}}{d^{2}}+\frac{\left(\bar{X}_{N}-T\right)^{2}}{d^{2}} ; \bar{X}_{N} \in\left\{\bar{X}_{L}, \bar{X}_{U}\right\}, s_{N}=\left\{s_{L}, s_{U}\right\}
$$

where $\bar{X}_{L}=\sum_{i=1}^{n} x_{i}^{L} / n_{L}, \bar{X}_{U}=\sum_{i=1}^{n} x_{i}^{U} / n_{U}, s_{L}=\sqrt{\sum_{i=1}^{n}\left(x_{i}^{L}-\bar{X}_{L}\right)^{2} / n_{L}}$ and $s_{U}=\sqrt{\sum_{i=1}^{n}\left(x_{i}^{U}-\bar{X}_{U}\right)^{2} / n_{U}}$.

The proposed sampling plan is stated as follows:

Step1: Select a random sample of size $n_{N} \in\left\{n_{L}, n_{U}\right\}$ from the lot of the product and compute $\hat{L}_{N e}$; $\bar{X}_{N} \in\left\{\bar{X}_{L}, \bar{X}_{U}\right\}, s_{N}=\left\{s_{L}, s_{U}\right\}$.

Step2: Accept the lot of the product if $\hat{L}_{N e} \leq k_{N} ; k_{N} \in\left\{k_{a L}, k_{a U}\right\}$, where $k_{N}$ is the neutrosophic acceptance number.

So, the proposed sampling plan has two parameters, $n_{N} \in\left\{n_{L}, n_{U}\right\}$ and $k_{N} \in\left\{k_{a L}, k_{a U}\right\}$. The proposed plan reduces to the plan put forth by [1] when $n_{L}=n_{U}$. The neutrosophic operating characteristic (NOC) function of the proposed plan is derived as follows:

$$
P_{N a}=P\left\{\hat{L}_{N e} \leq k_{N}\right\} ; n_{N} \in\left\{n_{L}, n_{U}\right\}, \bar{X}_{N} \in\left\{\bar{X}_{L}, \bar{X}_{U}\right\}, s_{N}=\left\{s_{L}, s_{U}\right\}, k_{N} \in\left\{k_{a L}, k_{a U}\right\}
$$

By following [1], $\hat{L}_{N e}$ is distributed as $L_{N e} \chi_{n_{N}}^{2} / n_{N}$, where $\chi_{n_{N}}^{2}$ is a neutrosophic chi-square distribution. So, NOC function is obtained by:

$$
P_{N a}=P\left\{\chi_{n_{N}}^{2} \leq\left(n_{N} k_{N} / L_{N e}\right)\right\} ; n_{N} \in\left\{n_{L}, n_{U}\right\}, k_{N} \in\left\{k_{a L}, k_{a U}\right\}
$$

A neutrosophic sampling plan is considered to be efficient if it satisfies the producer's risk $\alpha$ and the consumer's risk $\beta$. So, NFOC must pass through $\left(p_{1}, 1-\alpha\right)$ and $\left(p_{2}, \beta\right)$, where $p_{1}$ is the acceptable quality level (AQL) and $p_{2}$ is the limiting quality level (LQL). So, the plan parameters of the 
proposed plan $n_{N} \in\left\{n_{L}, n_{U}\right\}$ and $k_{N} \in\left\{k_{a L}, k_{a U}\right\}$ can be determined by using following neutrosophic non-linear problem:

$$
\text { minimize } n_{N} \in\left\{n_{L}, n_{U}\right\}
$$

subject to

$$
P_{N a}\left(p_{1}\right)=\mathrm{P}\left(\chi_{n_{N}}^{2} \leq \frac{n_{N} k_{N}}{L_{A Q L}}\right) \geq 1-\alpha ; k_{N} \in\left\{k_{a L}, k_{a U}\right\} ; n_{N} \in\left\{n_{L}, n_{U}\right\}
$$

and

$$
P_{N a}\left(p_{2}\right)=\mathrm{P}\left(\chi_{n_{N}}^{2} \leq \frac{n_{N} k_{N}}{L_{L Q L}}\right) \leq \beta ; k_{N} \in\left\{k_{a L}, k_{a U}\right\} ; n_{N} \in\left\{n_{L}, n_{U}\right\}
$$

The plan parameters $n_{N} \in\left\{n_{L}, n_{U}\right\}$ and $k_{N} \in\left\{k_{a L}, k_{a U}\right\}$ of the proposed plan are determined using the search grid method through Equation (5) to Equation (7) and placed in Table 1 for various values of the $A Q L$ and $L Q L$. To save space, we consider only $\alpha=0.05, \beta=0.10$. The similar tables for any other values of $\alpha$ and $\beta$ can be made on the same lines. From Table 1 , we note that for the fixed value of $A Q L, n_{N} \in\left\{n_{L}, n_{U}\right\}$ and $k_{N} \in\left\{k_{a L}, k_{a U}\right\}$ decreases as the $L Q L$ increases. So, a smaller $n_{N} \in\left\{n_{L}, n_{U}\right\}$ is needed for the lot sentencing for the higher values of the $L Q L$.

Table 1. The plan parameters when $\alpha=0.05, \beta=0.10$.

\begin{tabular}{cccccc}
\hline$p_{1}$ & $p_{2}$ & $n_{N}$ & $k_{N}$ & $L_{N}\left(p_{1}\right)$ & $L_{N}\left(p_{2}\right)$ \\
\hline & 0.002 & {$[39,78]$} & {$[0.0014,0.0016]$} & {$[0.9503,0.9994]$} & {$[0.0794,0.0987]$} \\
& 0.003 & {$[22,33]$} & {$[0.0019,0.0021]$} & {$[0.9934,0.9998]$} & {$[0.0962,0.0997]$} \\
& 0.004 & {$[16,24]$} & {$[0.0023,0.0026]$} & {$[0.9978,1.000]$} & {$[0.0951,0.0951]$} \\
0.001 & 0.006 & {$[13,15]$} & {$[0.0031,0.0034]$} & {$[0.9999,1.0000]$} & {$[0.0838,0.0978]$} \\
& 0.008 & {$[9,11]$} & {$[0.0037,0.004]$} & {$[0.9999,1.0000]$} & {$[0.0954,0.0966]$} \\
& 0.010 & {$[7,9]$} & {$[0.0040,0.0042]$} & {$[0.9998,1.0000]$} & {$[0.0747,0.0971]$} \\
& 0.015 & {$[5,7]$} & {$[0.0048,0.006]$} & {$[0.9998,1.000]$} & {$[0.0971,0.0988]$} \\
& 0.020 & {$[4,6]$} & {$[0.0053,0.0073]$} & {$[0.9997,1.000]$} & {$[0.0986,0.0994]$} \\
\hline \multirow{2}{*}{0.0025} & 0.030 & {$[5,8]$} & {$[0.0096,0.130]$} & {$[0.9982,1.000]$} & {$[0.0982,0.0988]$} \\
& 0.050 & {$[3,6]$} & {$[0.0097,0.018]$} & {$[0.9913,1.000]$} & {$[0.0956,0.0995]$} \\
\hline \multirow{2}{*}{0.005} & 0.050 & {$[7,10]$} & {$[0.0200,0.024]$} & {$[0.9998,1.0000]$} & {$[0.0971,0.0959]$} \\
& 0.100 & {$[4,6]$} & {$[0.0260,0.036]$} & {$[0.9997,1.0000]$} & {$[0.0956,0.0963]$} \\
\hline \multirow{2}{*}{0.01} & 0.020 & {$[49,53]$} & {$[0.0150,0.0152]$} & {$[0.9867,0.9913]$} & {$[0.0985,0.0994]$} \\
& 0.030 & {$[15,18]$} & {$[0.0169,0.0181]$} & {$[0.9546,0.9812]$} & {$[0.0955,0.0998]$} \\
\hline \multirow{2}{*}{0.03} & 0.060 & {$[78,85]$} & {$[0.0480,0.0485]$} & {$[0.9994,0.9997]$} & {$[0.0987,0.0999]$} \\
& 0.090 & {$[56,60]$} & {$[0.0690,0.0696]$} & {$[1.0000,1.0000]$} & {$[0.0989,0.09999]$} \\
\hline \multirow{2}{*}{0.05} & 0.100 & {$[53,56]$} & {$[0.0760,0.0765]$} & {$[0.9913,0.9935]$} & {$[0.0981,0.0994]$} \\
& 0.150 & {$[26,29]$} & {$[0.0990,0.102]$} & {$[0.9979,0.9992]$} & {$[0.0958,0.0986]$} \\
\hline
\end{tabular}

\section{Application of the Proposed Plan}

In this section, we discuss the application of the proposed sampling plan with the aid of company data. The data are from a particular model of an amplified pressure sensor with specification limits; $T=2.0 \mathrm{~V}, U S L=2.1 \mathrm{~V}$, and $L S L=1.9 \mathrm{~V}$. Similar data were used by [1]. For the inspection of the product, suppose that $A Q L=0.001, L Q L=0.002, \alpha=5 \%$, and $\beta=10 \%$. Suppose that the experimenter is unsure of the suitable sample size and corresponding acceptance number for the inspection of the product at $\alpha=5 \%$ and $\beta=10 \%$. The neutrosophic plan parameters from Table 1 are $n_{N}=\{39,78\}$ and $k_{N} \in\{0.0014,0.0016\}$. This means that the sample size should be between 39 and 78 for the inspection of the product. Suppose that the experimenter decided to select a random sample of size of 66. Neutrosophic observations for the data of the case of $n=66$ are shown in Table 2. 
Table 2. The data from amplified sensors.

\begin{tabular}{cccc}
\hline Column 1 & Column 2 & Column 3 & Column 4 \\
\hline$[1.9422,1.9422]$ & {$[1.9651,1.9651]$} & {$[2.0230,2.0230]$} & {$[1.9712,1.9712]$} \\
{$[1.9738,1.9938]$} & {$[1.9541,1.9541]$} & {$[1.9800,2.0980]$} & {$[1.9596,1.9596]$} \\
{$[2.0001,2.0001]$} & {$[1.9659,1.9659]$} & {$[1.9955,1.9955]$} & {$[1.9842,1.9842]$} \\
{$[1.9897,1.9897]$} & {$[1.9836,1.9836]$} & {$[1.9891,1.9891]$} & {$[1.9608,1.9608]$} \\
{$[2.0106,3.000]$} & {$[1.9885,1.9885]$} & {$[1.9704,1.9704]$} & {$[1.9882,1.9882]$} \\
{$[1.9640,1.9640]$} & {$[2.0187,2.0187]$} & {$[1.9616,1.9716]$} & {$[1.9865,1.9865]$} \\
{$[1.9841,1.9841]$} & {$[1.9919,1.9919]$} & {$[1.9737,1.9737]$} & {$[1.9958,1.9958]$} \\
{$[1.9841,1.9841]$} & {$[1.9570,1.9570]$} & {$[1.9610,1.9610]$} & {$[2.0015,2.0015]$} \\
{$[1.9668,1.9668]$} & {$[1.9696,2.0212]$} & {$[2.0334,2.0334]$} & {$[1.9656,1.9656]$} \\
{$[2.0114,2.0521]$} & {$[1.9861,1.9861]$} & {$[1.9743,1.9743]$} & {$[1.9594,1.9841]$} \\
{$[1.9837,1.9837]$} & {$[1.9424,1.9424]$} & {$[1.9744, \mathbf{1 . 9 9 4 4}]$} & {$[1.9605,1.9605]$} \\
{$[\mathbf{1 . 9 7 7 9}, \mathbf{1 . 9 9 9 9 ]}$} & {$[2.0072,2.0072]$} & {$[1.9875,1.9875]$} & {$[1.9781,1.9781]$} \\
{$[1.9971,1.9971]$} & {$[1.9963,1.9963]$} & {$[1.9375,1.9375]$} & {$[1.9941,1.9941]$} \\
{$[1.9611,1.9611]$} & {$[1.9729,1.9729]$} & {$[1.9992,1.9992]$} & {$[1.9925,1.9925]$} \\
{$[1.9964,1.9964]$} & {$[1.9614,2.0000]$} & {$[1.9768,1.9768]$} & {$[1.9991,1.9991]$} \\
{$[1.9748,1.9748]$} & {$[1.9664,1.9664]$} & {$[2.0035,2.0035]$} & {$[1.9822,1.9822]$} \\
{$[2.0030,4.0512]$} & {$[1.9786,1.9786]$} & {$[1.9720,1.9720]$} & {$[1.9834,1.9834]$} \\
\hline
\end{tabular}

The neutrosophic mean and standard deviation (SD) for the data are given as $\bar{X}_{N} \in\{1.9806,2.0222\}$ and $s_{N}=\{0.0191,0.2740\}$. The neutrosophic statistic for the proposed plan is computed as follows:

$$
\hat{L}_{N e}=\left\{\left(\frac{1}{d^{2}}\left\{S_{n L}^{2}+\left(\bar{X}_{L}-T\right)^{2}\right\}\right),\left(\frac{1}{d^{2}}\left\{S_{n U}^{2}+\left(\bar{X}_{U}-T\right)^{2}\right\}\right)\right\}
$$

where $d=0.1$.

$$
\hat{L}_{N e} \in\{0.0739,7.5598\}
$$

According to the acceptance/rejection criteria of the proposed plan, the lot of product will be rejected if $\hat{L}_{N e} \in\{0.0739,7.5598\}>k_{N} \in\{0.0014,0.0016\}$.

\section{Concluding Remarks}

A new sampling plan using neutrosophic process loss consideration is proposed in this paper. The operating characteristic function is given for the proposed sampling plan. The neutrosophic fuzzy non-linear problem is given to determine the plan parameters for the specified set of parameters. The proposed sampling plan is more flexible and can be applied when experimenters are uncertain about the selection of parameters, when some observations of the variable under study are unclear. The proposed plan is the generalization of the plan based on classical statistics, which assumes certainty in parameters and observations. The application of the proposed plan is shown using real data from a factory. Future research may involve employing the proposed plan for big data applications. Moreover, future study may involve more fields of research that employ classical statistics, which can be generalized to neutrosophic statistics in cases when there is indeterminacy, conflicting information, or vague and incomplete information.

Acknowledgments: The authors are deeply thankful to the editor and reviewers for their valuable suggestions to improve the quality of this manuscript. This project was funded by the Deanship of Scientific Research (DSR) at King Abdulaziz University, Jeddah, under grant no, 130-58-D1439. The authors acknowledge with thanks the DSR for technical and financial support.

Conflicts of Interest: The authors declare no conflict of interest. 


\section{References}

1. Yen, C.-H.; Chang, C.-H. Designing variables sampling plans with process loss consideration. Commun. Stat.-Simul. Comput. 2009, 38, 1579-1591. [CrossRef]

2. Aslam, M.; Yen, C.-H.; Jun, C.-H. Variable repetitive group sampling plans with process loss consideration. J. Stat. Comput. Simul. 2011, 81, 1417-1432. [CrossRef]

3. Pearn, W.-L.; Wu, C.-W. Variables sampling plans with PPM fraction of defectives and process loss consideration. J. Oper. Res. Soc. 2006, 57, 450-459. [CrossRef]

4. Aslam, M.; Yen, C.-H.; Chang, C.-H.; Jun, C.-H. Multiple states repetitive group sampling plans with process loss consideration. Appl. Math. Model. 2013, 37, 9063-9075. [CrossRef]

5. Aslam, M.; Yen, C.-H.; Chang, C.-H.; Jun, C.-H. Multiple dependent state variable sampling plans with process loss consideration. Int. J. Adv. Manuf. Technol. 2014, 71, 1337-1343. [CrossRef]

6. Seifi, S.; Nezhad, M.S.F. Variable sampling plan for resubmitted lots based on process capability index and Bayesian approach. Int. J. Adv. Manuf. Technol. 2017, 88, 2547-2555. [CrossRef]

7. Wang, Z.; Zhou, X.; Yuan, X.; Wang, L.; Huang, D. Acceptance sampling plan of quality inspection for ocean dataset. J. Spat. Sci. 2015, 60, 329-339. [CrossRef]

8. Yan, A.; Liu, S. Designing a repetitive group sampling plan for Weibull distributed processes. Math. Probl. Eng. 2016, 2016, 5862071. [CrossRef]

9. Yan, A.; Liu, S.; Azam, M. Designing a multiple state repetitive group sampling plan based on the coefficient of variation. Commun. Stat.-Simul. Comput. 2017, 46, 7154-7165. [CrossRef]

10. Afshari, R.; Gildeh, B.S. Construction of fuzzy multiple deferred state sampling plan. In Proceedings of the Fuzzy Systems Association and 9th International Conference on Soft Computing and Intelligent Systems (IFSA-SCIS), Otsu, Japan, 27-30 June 2017.

11. Kanagawa, A.; Ohta, H. A design for single sampling attribute plan based on fuzzy sets theory. Fuzzy Sets Syst. 1990, 37, 173-181. [CrossRef]

12. Tamaki, F.; Kanagawa, A.; Ohta, H. A Fuzzy Design of Sampling Inspection Plans by Attributes. J. Jpn. Soc. Fuzzy Theory Syst. 1991, 3, 211-212. [CrossRef]

13. Sadeghpour Gildeh, B.; Baloui Jamkhaneh, E.; Yari, G. Acceptance single sampling plan with fuzzy parameter. Iran. J. Fuzzy Syst. 2011, 8, 47-55.

14. Divya, P. Quality interval acceptance single sampling plan with fuzzy parameter using poisson distribution. Int. J. Adv. Res. Technol. 2012, 1, 115-125.

15. Turanoğlu, E.; Kaya, İ.; Kahraman, C. Fuzzy acceptance sampling and characteristic curves. Int. J. Comput. Intell. Syst. 2012, 5, 13-29. [CrossRef]

16. Jamkhaneh, E.B.; Gildeh, B.S. Acceptance Double Sampling Plan using Fuzzy Poisson Distribution 1. World Appl. Sci. J. 2012, 15, 1692-1702.

17. Jamkhaneh, E.B.; Gildeh, B.S. Sequential sampling plan using fuzzy SPRT. J. Intell. Fuzzy Syst. 2013, 25, 785-791.

18. Venkateh, A.; Elango, S. Acceptance sampling for the influence of TRH using crisp and fuzzy gamma distribution. Aryabhatta J. Math. Inform. 2014, 6, 119-124.

19. Elango, S.; Venkatesh, A.; Sivakumar, G. A fuzzy mathematical analysis for the effect of trh using acceptance sampling plans. Int. J. Pure Appl. Math. 2017, 117, 1-7.

20. Smarandache, F. Neutrosophy: Neutrosophic Probability, Set, and Logic: Analytic Synthesis E Synthetic Analysis; American Research Press: Rehoboth, DE, USA, 1998; p. 105.

21. Ye, J.; Chen, J.; Yong, R.; Du, S. Expression and analysis of joint roughness coefficient using neutrosophic number functions. Information 2017, 8, 69. [CrossRef]

22. Chen, J.; Ye, J.; Du, S. Scale effect and anisotropy analyzed for neutrosophic numbers of rock joint roughness coefficient based on neutrosophic statistics. Symmetry 2017, 9, 208. [CrossRef]

23. Johnson, T. The relationship of Cpm to squared error loss. J. Q. Technol. 1992, 24, 211-215. [CrossRef]

(C) 2018 by the author. Licensee MDPI, Basel, Switzerland. This article is an open access article distributed under the terms and conditions of the Creative Commons Attribution (CC BY) license (http:/ / creativecommons.org/licenses/by/4.0/). 